\title{
Para quem você dança?
}

\section{Who do you dance for?}

\author{
Nara Cálipo I Graziela Estela Fonseca Rodrigues \\ Universidade Estadual de Campinas I Campinas, SP, Brasil. \\ nacalipo@gmail.com I ORCID: https://orcid.org/0000-0002-3097-7416.
}

DOI: $10.20396 /$ conce.v8i2.8656488.

Submetido em: 07/09/2019 | Aceito em: 12/06/2019 | Publicado em: 20/12/2019.

\section{Resumo}

O presente artigo tem como objetivo discutir a criação de uma obra de dança e a análise de sua recepção considerando o contexto e as espectadoras para as quais a mesma foi criada e apresentada: mulheres quebradeiras de coco babaçu e baiadoras de Terecô. O método de pesquisa e criação em dança, Bailarino-Pesquisador-Intérprete (BPI), foi utilizado na pesquisa e criação que deu origem aos dados em discussão. No percurso aqui descrito e discutido, procura-se evidenciar o aprofundamento propiciado pelo deslocamento de locais tidos como normativos para a criação e apresentação de obras coreográficas, para topologias tidas como outras, tais como comunidades e terreiros de Terecô ao norte do Estado do Tocantins.

\section{Abstract}

This article aims to discuss the creation of a dance work and the analysis of its reception considering the context and the spectators for whom it was created and presented: female babassu coconut breakers and Terecô dancers. The dance research and creation method, DancerResearcher-Performer (BPI), was used for the research and creation to gather the data under in question. In the journey hereby described and discussed, the purpose is to highlight the deepening provided by the displacement of places considered as normative for the creation and

\section{KEYWORDS}

Dancer-ResearcherPerformer. Creative Process. Reception. 
presentation of choreographic works, for topologies considered as others, such as communities and terreiros of Terecô in the north of Tocantins State. 
O Bailarino-Pesquisador-Intérprete (BPI), um método prático-teórico de pesquisa e criação em Dança, apresenta, desde sua criação, o procedimento nomeado "Retorno ao Campo". Retornar ao Campo diz respeito à ação de apresentar às pessoas com as quais se coabitou em pesquisa de campo, a obra fruto da experiência em questão. Tal procedimento detém uma complexidade que ganha novos desdobramentos de acordo com o campo de pesquisa e com a situação em que ocorre.

No BPI, são campos de pesquisa comunidades, nichos sociais, festejos e rituais, muitas vezes com tons de esquecimento e invisibilidade por conta, sobretudo, de seu contexto social, étnico racial, religioso e região que habitam, ocupando, assim, uma marginalidade que não é sempre e nem somente geográfica, mas principalmente estabelecida pelo poder econômico que achata existências em suas especificidades.

O foco da pesquisa de campo localizada no eixo coabitar com a fonte do BPI é o encontro entre pesquisadoras e baiadoras, rezadeiras, boias-frias, mulheres e também homens que resistem habitando tais camadas sociais, em um trabalho primoroso das relações humanas. Trabalho este que é desenvolvido na estrutura do método que se estabelece principalmente em três eixos: "Inventário no Corpo, Coabitar com a Fonte e Estruturação da Personagem" (RODRIGUES, 2003), também nas ferramentas utilizadas em todas as etapas (RODRIGUES, 2010) e uma infinitude de procedimentos em constante criação em cada processo em andamento. $\mathrm{O}$ objetivo é mover para o desenvolvimento de algo (seja a criação em dança, a coabitação, a escrita sobre as práticas e/ ou outros aspectos) que esteja vivo. Embora se conte com extensa e densa bibliografia sobre o BPI, assim como obras e espetáculos de dança criados com o método, e uma prática permanente há mais de 30 anos em universidades e escolas do ensino formal, públicas e privadas, há um trabalho empenhado em não cristalizar seus modos de fazer e pesquisar.

Um desses frutos do BPI, uma pesquisa de doutorado orientada pela criadora do método, se propôs a analisar a recepção da obra pela fonte coabitada, isso quer dizer: 1 . criar uma obra endereçada às pessoas com as quais se coabitou em pesquisa de campo; 2. retornar a este campo; 3. dançar a obra criada para as pessoas com as quais se coabitou; 4. após essa ação, realizar análise de como a obra foi recebida por seus espectadores. Desta forma, a pesquisa a ser discutida neste artigo, que é sobre o BPI, também o utilizou como método e traz um 
aprofundamento a partir do uso da ferramenta Retorno ao Campo.

Assim como pontuado anteriormente, a complexidade do Retorno ao Campo se desdobra de acordo com alguns aspectos, tais quais: o campo em questão, o tipo de obra a ser apresentada e, principalmente, o viés adotado para o procedimento. No caso aqui a ser apresentado e discutido, deteve-se sob o viés da recepção da obra e da criação da mesma endereçada às pessoas coabitadas. Nesse percurso, a questão das escolhas focalizando uma abordagem ética foi imperativa. Estas escolhas, por sua vez, foram tomadas a partir de uma série de questionamentos lançados e repetidos diversas vezes pela diretora da obra e orientadora da pesquisa. Tal estado de questionamento possibilitou o aparecimento de fissuras irreversíveis na forma de criar e pensar a criação da bailarina-pesquisadora.

\section{Retornar ao campo: implicações éticas nos encontros de diferentes naturezas e topologias}

Desde o espetáculo que fundou o BPI, "Graça Bailarina de Jesus ou Sete Linhas de Umbanda Salvem o Brasil", de Graziela Rodrigues, criadora do BPI, retornar ao campo com a obra nascida do encontro e coabitação entre pessoas pesquisadas e bailarina-pesquisadora, é uma constante (COSTA, 2012). A realização desta etapa desencadeia uma série de aprofundamentos para a pesquisa e sua obra artística, mas há, sobretudo, uma relação de respeito em relação às comunidades pesquisadas, uma vez que se leva a obra (assim como demais materiais provenientes da coabitação) e se abre a escuta para a recepção da mesma. Trata-se de uma atitude ética perante a troca que ocorreu junto ao campo de pesquisa, isto porque a obra está carregada de conteúdos emergentes das relações estabelecidas.

No que concerne ao aspecto da ética neste fazer, o mesmo está ancorado no exercício da consciência. Assim como pontuado por Chaui (2010, p. 433) "Para que haja conduta ética é preciso que exista o agente consciente". Ainda segundo a autora, tal agente detém conhecimento acerca das diferenças entre:

bem e mal, certo e errado, permitido e proibido, virtude e vício. A consciência moral não só conhece tais diferenças, mas também reconhece-se como capaz de julgar o valor dos atos e das condutas e de agir em conformidade com os valores morais, sendo por isso responsável por suas ações e seus sentimentos e pelas conseqüências do que faz e sente. Consciência e responsabilidade são condições indispensáveis da vida ética. (CHAUI, 2010, p. 433.) 
Quando, no BPI, se abre à coabitação com indivíduos situados em contextos culturais e sociais distintos do local de origem do pesquisador, parte-se da premissa da diferença de classes sociais, o que incide em "várias morais". Ainda segundo Chaui (2010), a moral diz respeito aos valores que cada sociedade estabelece em relação ao "bem e ao mal, ao permitido e ao proibido, e à conduta correta, válidos para todos os seus membros" (ibid. p. 437). Não se trata, no entanto, da fixação de regras, mas de uma delicadeza no adentrar em locais que podem operar de uma forma diferente da sua, com a qual, muitas vezes, não se está familiarizado. No âmbito da pesquisa de campo do eixo Cohabitar com a Fonte, há um estado permanente de observação com um "olhar do corpo todo", sobre as especificidades do campo. Neste sentido, o bailarino também tem recursos para atentar à maneira como suas percepções sobre a diferença reverberam em si. O intuito é estabelecer uma relação de respeito às singularidades do contexto e seus indivíduos.

No recorte do Retorno ao Campo, ao abrir-se para receber as impressões dos espectadores-fontes, o bailarino-pesquisador busca abrir-se também à validação por parte dos mesmos, uma vez que algo presente na obra diz respeito ao que foi a experiência de coabitação. A escuta para o que surge dessa recepção envolve o despojar-se de um desejo de algum tipo de aceitação, uma vez que o que importa, neste âmbito, é a leitura desses espectadores frente ao que emergiu do contato anterior.

Pontua-se que, na ação de dançar para a fonte coabitada, ocorrem ainda outros aprofundamentos: tendo em vista que as impressões provenientes dos espectadores-coabitados carregam valores no contexto em que habitam, há a possibilidade de refinar os dados apreendidos anteriormente; há a ocorrência de um novo campo, mas agora com o corpo performando a obra (e personagem) e por isso, metamorfoseado pelo/no encontro com as pessoas coabitadas, as dinâmicas do contexto, sua cosmologia, entre outros aspectos.

Várias pesquisas do BPI já adentraram a esta etapa do processo, mas com diferentes focos. A pesquisa de mestrado de Elisa Costa, orientada por Graziela Rodrigues, investigou o procedimento de Retorno ao Campo com o objetivo de "evidenciar as trocas e interferências entre os Xavante e 'Nascedouro', por meio do que surgiu no corpo da intérprete a partir desse retorno à aldeia" (COSTA, 2012, p.14). A pesquisa de mestrado de Paula Teixera (2007) não possuía a etapa de Retorno ao Campo como foco, mas tem a ocorrência do mesmo após 
decisão tomada junto a sua orientadora. Nesta conjuntura, seu interesse se detinha, segundo ela: "[...] e eu, curiosa para saber o que eles achariam da apresentação e, principalmente, o que ela ressoaria neles enquanto identificação e /ou estranhamento" (TEIXEIRA, 2007, p. 94). Já Larissa Turtelli debruçou-se sobre a recepção da obra cuja pesquisa de campo se deu em diversos terreiros de umbanda, tanto por espectadores em locais oficiais da dança, quando no próprio terreiro de umbanda (TURTELLI; RODRIGUES, 2014). Além dessas pesquisas citadas, há uma série de exemplos de ocorrências ${ }^{1}$ de Retorno ao Campo com diferentes características.

A pesquisa de doutorado "Para quem você Dança? A criação e a recepção da dança no método Bailarino-Pesquisador-Intérprete: uma experiência com as mulheres quebradeiras de coco babaçu e com o Terecô" propôs como objetivo principal se debruçar sobre a recepção da obra pela fonte coabitada. A efetivação deste objetivo envolveu olhar para o que estava em questão por meio de diferentes perspectivas: tanto da bailarina que vivenciou a experiência e possui esse dado corporificado nas/das apresentações à fonte coabitada, da mesma analisando posteriormente os diversos materiais audiovisuais captados na ocasião das apresentações, como da diretora-orientadora que também esteve in loco e analisou o material.

Assinala-se que o percurso da pesquisa iniciou-se ainda durante o mestrado, de forma que o contato com o campo de pesquisa ocorreu ao longo de quatro anos consecutivos, entre as pesquisas de mestrado e doutorado. Neste caminho, surgiram questões que convocaram o olhar a ajustar suas lentes frente ao material com o qual estava lidando. Na operação do método BPI, o primor nesta lida se dá, sobretudo, olhar sempre para as especificidades das pessoas coabitadas, com o objetivo de não incidir em uma lida violenta. Para Butler (2015, p. 16), a norma ética deve ser constantemente "submetida à revisão crítica", uma vez que "se ela ignora as condições sociais, que também são as condições sob as quais toda ética deve ser apropriada, aquele ethos torna-se violento".

Nas discussões do grupo de pesquisa, nas orientações, nos procedimentos, nas leituras básicas para o desenvolvimento com/no BPI, temas como etnocentrismo, alteridade e psicologia voltada para as questões psicanalíticas são amplamente abordados. É possível afirmar, inclusive, que o próprio eixo Inventário no Corpo cumpre um papel de viabilizar a feitura de uma dança

${ }^{1}$ Para mais exemplos e informações, consultar Costa (2012). 
e pesquisa onde a ética esteja em pauta permanentemente. O seu objetivo é propiciar que o/a bailarino/a entre contrato com sua história gestual através da prática de dança (por meio da Estrutura Física e Anatomia Simbólica) e também de uma pesquisa, isto para que ele se situe socialmente, historicamente, fisiologicamente, aproximando-se dos valores cristalizados em si, tais como preconceitos e discriminações veladas (RODRIGUES, 2003). Ao se aproximar dessa realidade e aceitá-la como parte de si, o bailarino-pesquisador toma consciência do risco de incidir no campo com tais valores, muitas vezes nunca questionados por serem naturalizados pela família e pela sociedade.

SegundoChaui(2000),osvaloresdizemrespeitoàquiloqueétidocomobom ouruim, passíveldeserrecompensadoourepreendido. Aindasegundotalautora:

somos formados pelos costumes de nossa sociedade, que nos educa para respeitarmos e reproduzirmos os valores propostos por ela como bons e, portanto, como obrigações e deveres. Dessa maneira, valores e maneiras parecem existir por si e em si mesmos, parecem ser naturais e intemporais, fatos ou dados com os quais nos relacionamos desde o nosso nascimento: somos recompensados quando os seguimos, punidos quando os transgredimos. (Ibid. p. 437.)

No contato com a própria história pessoal, seja através de uma busca realizada fora do estúdio, como também em uma pesquisa do corpo em movimento, ao perceber, desdobrar e elaborar conteúdos oriundos das manifestações populares brasileiras que despertam relações de proximidade-distanciamento, familiaridade-estranheza, empatia-rejeição, o bailarino-pesquisador perpassa por um questionamento dos valores estabelecidos e antes dificilmente contatados sob um viés crítico, porém não julgador (RODRIGUES, 1997). Embora este seja um estado de maior proeminência no eixo Inventário no Corpo, ele é também de suma importância no eixo Coabitar com a Fonte, onde o contato com a diferença faz eclodir tenazmente julgamentos, preconceitos e projeções, com os quais o bailarino está pronto para lidar com, não só no aspecto intelectual, mas também corporal.

\section{Processo de criação: da superfície à profundeza.}

A pesquisa de doutorado aqui em questão teve sua pesquisa de campo do eixo Coabitar com a Fonte realizada ao norte do estado do Tocantins, na região conhecida como Bico do Papagaio, onde situam-se babaçuais em virtude da transição de ecossistemas que ali se encontram: cerrado e mata amazônica. Assim, somada a questões sociais e econômicas, a principal atividade das mulheres 
que habitam essa região é a quebra do coco babaçu. Portanto, a primeira ida a este campo teve como objetivo imergir no universo das mulheres quebradeiras de coco babaçu em comunidades rurais da região em questão. Ao longo de três semanas, nas quais foi possível permanecer em duas comunidades distintas, a bailarina-pesquisadora viveu um cotidiano junto às quebradeiras de coco, inclusive no aprendizado da quebra do coco babaçu. Este primeiro contato frutificou-se em diversas idas ao campo nos anos que seguiram, as quais abriram uma série de questões que dizem respeito ao processo criativo instaurado, a análise dos movimentos e escrita sobre os corpos com os quais se coabitou.

A manifestação religiosa Terecô, que conta com rituais de incorporação de entidades espirituais denominadas Encantados, foi um ponto de proeminência ao longo da pesquisa, em que a pesquisadora se deteve ao longo das pesquisas de campo. O Terecô possui a função de restabelecer o equilíbrio, seja ele físico, espiritual ou social (CÁLIPO, 2012). O contexto no qual ocorre é de precariedade extrema no que diz respeito ao acesso a uma estrutura tanto tangível, tal como a água encanada, pavimentação, sistema de esgoto, sistema de saúde efetivo, quanto intangível.

Ao se propor, junto da orientadora e diretora do trabalho, a criar para essas mulheres com as quais coabitou, toda concepção que a pesquisadora tinha acerca da criação e elaboração de uma obra artística precisou ser revista, muitas vezes refutada. Isto porque nesta lida primorosa com o/a outro/a, seja da diretora para com a bailarina em processo, da bailarina com as pessoas com as quais coabitou, ou com os espectadores com os quais se pretende comunicar, é preciso considerar as singularidades e suas especificidades.

Havia, a princípio, uma preocupação com um determinado tipo de "acabamento cênico", denunciando uma preocupação estética mais próxima da superfície do corpo que de suas profundidades. Isto, obviamente, não estava situado em um plano consciente da bailarina-pesquisadora. Embora haja uma estética proveniente da dramaturgia do BPI em função de sua estrutura como método, ela não é pautada em uma rigidez, ou seja, não há uma escolha fixa por determinada estética, principalmente porque as escolhas se pautam no que eclode do corpo em processo. Neste aspecto é que tange a "profundidade" referida, pois o material a ser trabalhado na criação é o que o corpo deixa escapar, se lida "com a realidade possível do intérprete e com sua singularidade" (MELCHERT, 2007), com aquilo que ainda não está talhado 
pelas camadas do consciente, adaptado aos valores impregnados na pessoa.

Embora não haja uma preocupação em comunicar uma mensagem decodificada, ou fazer-se entender linearmente, no BPI a relação com o espectador recebe uma atenção especial, em que o bailarino procura sentir, enquanto em cena, o que vem de sua plateia e deixar, de forma conduzida, com que a personagem que ali habita se impregne disso e responda, na sua performance, ao que vem. Turtelli (2014, p.43) detalha que "há da parte do intérprete uma postura ativa nos dois sentidos, no de fazer questão que o público perceba o que a personagem em seu corpo está sentindo e no de fazer questão de perceber o que o público está sentindo". Interessa a este tipo de trabalho um tipo de porosidade que permite o trânsito consciente de sensações, emoções e movimentos entre bailarino e espectadores.

Neste sentido, considerando o tempo de prática da bailarina-pesquisadora que se propôs a essa experiência, havia registros contundentes de como se dá essa relação em constante abertura, troca e busca por escutar, com o corpo, os espectadores. Ocorre que foi necessário considerar primeiramente a diferença dos contextos nos quais as experiências anteriores haviam se dado, pois embora a maioria delas não tenham acontecido em lugares considerados normativos para as artes do espetáculo, mas em galpões, ginásios, entre outros, os espectadores habitavam um ambiente próximo ao seu: a cidade. No caso de sua experiência de Retorno ao Campo, o mesmo ocorreu em um evento no qual foi apresentado um espetáculo cuja criação não foi endereçada para um público específico, o que difere diametralmente da proposta que veio em seguida: criar e dançar para elas, as mulheres coabitadas.

O primeiro aspecto considerado foi a relação que as mulheres das comunidades pesquisadas possuíam com artes espetaculares tais como: dança, teatro e circo. O que levou à reflexão de quais relações estabeleciam com a dança, principal meio de acontecimento do Terecô, independente do contexto tido como espetacular. Trata-se de um aspecto que incide diretamente na questão ética na lida com a diferença: considerá-la e exercitar a relativização e a crítica. Foi utilizado como estratégia o questionamento a essas pessoas para as quais havia a intenção de criar para e tê-las como interlocutoras. O primeiro passo foi compreender com quais códigos, no sentido da performance, esses indivíduos lidavam. Havia familiaridade com a estrutura quase institucionalizada das artes da cena, na qual o espaço se divide entre palco e plateia 
(independente de sua disposição), o tempo com um começo e um fim no qual a atenção se detém quase somente ao que ali ocorre, e também em relação ao caráter ficcional do que ocorre em cena? Essas espectadoras não haviam experienciado um espetáculo das Artes da Cena (no sentido institucionalizado) e a relação com a dança era, sobretudo, através dos rituais de Terecô.

No Terecô, tudo começa com um "jeito ruim no corpo", que vai virando um "ficar meio ruim da cabeça", até "quase endoidar". Em algum momento, rebenta no corpo movimentos sem um delineamento, impulsos descontrolados, e as mulheres e meninas que vivem esse processo, saem correndo pelas matas, se atiram ao chão e às paredes, ferem-se. Uma mestra é chamada para lidar com a situação que, geralmente, está controlada por parentes e vizinhos que chegam a amarrar as mulheres para que os impulsos de movimento que as ferem, sejam contidos. Essa é a contundência da força com a qual se lida no Terecô.

Quando um episódio assim ocorre, não há dúvidas por parte da comunidade na qual a mulher está inserida. Às vezes uma vizinha escuta "um barulho estranho" que vem da casa ao lado e identifica a necessidade de checar o que acontece. Na presença da mulher que é acometida pelos impulsos corporais, essa outra mulher (vizinha, amiga, parente) vê que ocorre ali um processo do Terecô. Atenta-se às características modeladas no corpo da outra, bem como a dinâmica ali presente e, muitas vezes, identifica qual Encantado (entidade espiritual) está incorporada naquele corpo e, assim, quais os primeiros procedimentos a serem adotados antes de pedir socorro a uma mestra.

Trata-se de existências as quais possuem os sentidos aguçados e são necessários, inclusive, no cuidado com o outro (ou outra). Sua escuta, seu olhar, sua leitura do movimento e suas dinâmicas estão fundadas na sensibilidade. $\mathrm{O}$ afeto permeia as relações de cuidado no Terecô, em que a mestra acolhe o corpo físico e emocional de suas médiuns. Foi imprescindível considerar que essas eram as espectadoras para as quais a criação estava endereçada.

No que diz respeito ao momento da criação desta obra coreográfica, a bailarina-pesquisadora, quando em laboratórios dirigidos, passou a viver uma série de "travamentos" do corpo, "vazios" que permaneceram por meses. Há de se pontuar que, quando em processo, questões contatadas em campo podem disparar questões pessoais que devem ser trabalhadas e elaboradas, mas não desenvolvidas no âmbito da criação. Esse foi um dos aspectos presentes, 
levando a bailarina a vivenciar imagens (internas), sensações e emoções de mulheres desvitalizadas e perdidas, sustentadas por tripas, literalmente despedaçadas. A dificuldade na lida com tais conteúdos estava sediada não só na natureza dos mesmos, mas também em uma negação por parte da bailarina, que vivia como contraponto, uma idealização acerca do que viria a ser a obra.

A partir de então a diretora e orientadora passou a questionar: "para quem você quer dançar?" (CÁLIPO, 2016). Esta pergunta, que tomou seu tempo e muito trabalho para ser de fato compreendida pela intérprete, confrontava o movimento criativo da mesma, que até então perambulava ainda pelas superfícies do corpo, não tocando a fundo as profundezas das "mulheres de restos" que lhe habitavam. A diretora, ao lançar exaustivamente tal questionamento, estava engajada com os princípios do BPI e com as futuras espectadoras. Para adentrar em seus locais e dançar para elas, havia a demanda por um tipo de abertura que envolvia o despojamento de qualquer apego estético, e um agarrar-se firmemente nos sentidos impregnados no corpo. Aí a dificuldade nesta criação. A demanda por uma honestidade para com o que transbordava do corpo envolveu coragem, algumas vezes parida a fórceps, para lidar com os conteúdos distantes das idealizações a respeito do campo, a respeito do que o corpo geraria como obra, inclusive, a respeito de como esse corpo se apresentaria em cena. Em última instância, tratou-se de desgrudar-se dos desejos e apegar-se ao que estava de fato presente no corpo.

Dançar para espectadoras cuja dança ganha vida e permite viver uma outra narrativa através dos sentidos internos, gerando uma potência de movimento pautada na precisão, não demandou menos que um escancarar os próprios sentidos com o acabamento que era possível naquele momento.

\section{Afinal, para quem se dança? Questões da recepção}

Além dessa discussão estabelecida, antes de qualquer coisa, na prática artística, também instaurou-se um questionamento acerca da análise da recepção a qualestavapropostacomoobjetivoprincipal. Tendoemvistaqueacriaçãodaobra paraasmulheresquebradeirasdecocobabaçudemandoutalcuidado, pensarformas de análise da recepção considerando essas espectadoras, foi imprescindível.

No que tange o olhar sobre o espectador da obra, Desgranges discute, ancorado em Walter Benjamin, transformações estabelecidas principalmente a partir 
da modernidade, como responsáveis por alterações na percepção: "está premida por uma vivência urbana marcada pelos riscos e choques do cotidiano, pela padronização gestual, pelo consciente assoberbado, e pelo desestímulo à atuação de regiões profundas e sensíveis da psique" (DESGRANGES, 2008, p. 16).

Considerando tal espectador, com sua percepção alterada pelo meio, Pavis pontua a necessidade de o mesmo ter reabilitada "sua visão ávida, seu toque, seu olfato, sua cinestesia: sentidos esses muitas vezes esterilizados ou anestesiados" (PAVIS, 2003, p. 216).

Como descrito anteriormente, as espectadoras para as quais a obra foi endereçada, podem ser consideradas a antítese do estado de anestesiamento. Neste sentido, a bibliografia foi importante para apresentar os diversos aspectos a serem considerados no âmbito da análise da recepção, mas também para deflagrar a necessidade de se olhar para a especificidade das espectadoras.

A ação de considerar as diferenças entre o espectador abordado na bibliografia contatada e as espectadoras no recorte da pesquisa em questão consiste também em uma ética no trabalho das Artes da Cena. Não se trata de refutar modos de fazer, mas de, ao lidar com a pluralidade, submergir em campos receptivos distantes de uma lógica hegemônica. Trata-se de considerar as particularidades dos contextos e seus indivíduos.

Para a análise que se deu na pesquisa aqui em questão, foram realizados registros audiovisuais de diferentes perspectivas durante todas as apresentações. Utilizando tais dados junto da percepção da bailarina e da diretora-orientadora em campo, foram consideradas as transformações corporais dos espectadores como fonte para a aferição da recepção, uma vez que foram despertadas reações psicomotoras validadas para tal (OLIVEIRA, 2011). Os corpos das espectadoras, receptáculo dos conteúdos da obra, atuou como "participante, reativo e afetivo" (PAVIS, 2003 p. 215). Por meio da observação dos mesmos, foi possível verificar uma correspondência entre as reações corporais observadas nos registros, e os relatos que as mesmas fizeram após assistirem à obra.

Desta forma, a metodologia adotada para debruçar-se sobre a recepção desta obra, foi pautada na experiência em si, focalizando o discurso das espectadoras e espectadores, bem como as reações psicomotoras captadas nos registros audiovisuais. A recusa em olhar para a especificidade topológica do espectador 
assume o risco de incidir na universalização dos modos de perceber e receber.

Ao longo do percurso desta pesquisa, destacou-se o estado permanente de questionamento instaurado pela orientadora: afinal, para quem você quer dançar? O que você tem a dizer para elas? Também foram questionadas as maneiras de escutar, de olhar e sentir os materiais provenientes dos diversos encontros estabelecidos na pesquisa: entre pesquisadora e as mulheres quebradeiras de coco babaçu, entre pesquisadora e orientadora, entre pesquisadora e os registros audiovisuais provenientes da experiência. A assunção da diferença de posição entre pesquisaeseucampo, lançouaresponsabilidadedenãosetrabalharcomcertezas. 


\section{Referências}

BUTLER, J. Relatar a si mesmo. Crítica da violência ética. Belo Horizonte: Autêntica, 2015.

CÁLIPO, N. M. Para quem você dança? A criação e a recepção da dança no método Bailarino-Pesquisador-Intérprete: Uma experiência com as mulheres quebradeiras de coco babaçu e com o Terecô. 2016. 195 p. Tese (Doutorado em Artes da Cena), Universidade Estadual de Campinas, Campinas, São Paulo, 2016. Disponível em: <http:// repositorio.unicamp.br/jspui/bitstream/REPOSIP/320851/1/Calipo_ Nara1987-_D.pdf

CÁLIPO, N. M. Coabitares no corpo da bailarina-pesquisadora-intérprete: as mulheres quebradeiras de coco babaçu e seu Terecô. 129 p. Dissertação (Mestrado em Artes da Cena) - Instituto de Artes, Universidade Estadual de Campinas, Campinas, 2012. Disponível em: $<$ http://repositorio.unicamp.br/jspui/handle/REPOSIP/284571

CHAUI, M. Convite à Filosofia. São Paulo: Atica. 2000.

COSTA, E. M. Dançar para a Fonte Xavante: uma experiência do bailarino- pesquisador-intérprete de retorno à Terra Indígena de Pimentel Barbosa. 179 p. Dissertação (Mestrado em Artes da Cena) - Instituto de Artes, Universidade Estadual de Campinas, Campinas, 2012. Disponível em: <http://repositorio.unicamp.br/bitstream/REPOSIP/284599/1/Costa_ElisaMassariollida_M.pdf

DESGRANGES, F. Teatralidade tátil: alterações no ato do espectador. Sala Preta - Revista de Artes Cênicas do Programa de Pós-Graduação em Artes Cênicas da Universidade de São Paulo (USP), São Paulo, n. 8, p. 11-20, 2008. Disponível em: <http://www.revistas.usp. br/salapreta/article/view/57346/60328

MELCHERT, A. C. O desate criativo: estruturação da personagem a partir do Método BPI (Bailarino-Pesquisador-Intérprete). 2007. 158p. Dissertação (Mestrado em Artes) - Instituto de Artes, Universidade Estadual de Campinas, Campinas, 2007. Disponível em: <http:// 
repositorio.unicamp.br/jspui/handle/REPOSIP/285036

OLIVEIRA, I. M. G. As relações entre os programadores e espectadores de dança na cidade de São Paulo: O caso do TD - Teatro de Dança. 2011. 658 p. Tese (Doutorado em Artes) - Instituto de Artes, Universidade Estadual de Campinas, Campinas, São Paulo, 2011. Disponível em: <http://repositorio.unicamp.br/jspui/handle/REPOSIP/284346

PAVIS, P. A análise dos Espetáculos. São Paulo: Perspectiva, 2003.

RODRIGUES, G E. F. O Método BPI (Bailarino- Pesquisador-Intérprete) e o desenvolvimento da imagem corporal: reflexões que consideram o discurso de bailarinas que vivenciaram um processo criativo baseado neste método. 2003. 171p. Tese (Doutorado em Artes). Instituto de Artes da Universidade Estadual de Campinas, Campinas, 2003. Disponível em: <http://www.repositorio.unicamp.br/bitstream/ REPOSIP/284769/1/Rodrigues_Graziela_D.pdf

TEIXEIRA. P. C. O Santo que dança: uma vivência corporal a partir do eixo co-habitar com a fonte do Método Bailarino-Pesquisador-Intérprete (BPI). 2007. 195p. Dissertação (Mestrado em Artes) - Instituto de Artes, Universidade Estadual de Campinas, Campinas, 2007. Disponível em: <http://repositorio.unicamp.br/jspui/bitstream/ REPOSIP/285026/1Teixeira_PaulaCaruso_M.pdf

TURTELLI, L; RODRIGUES, G. O não dito ou além do que é dito diretamente: processos sensoriais e afetivos na recepção do espetáculo no método BPI. Conceição / Conception, Campinas,3(2), 42-51. Disponível em: <https://periodicos.sbu.unicamp.br/ojs/index.php/ conce/article/view/8647685/14564 